\title{
66
}

\section{Community collaboration to develop active learning environments in school libraries through telecommunications}

Harriet G. Taylor

Louisiana State University

Baton Rouge

USA

\author{
Ron Dupuis \\ Terry Thibodeaux \\ Scotlandville Magnet High \\ School \\ Baton Rouge \\ USA
}

\begin{abstract}
Schools in an economically distressed area were suffering from declining resources and stagnant curricula. A community project tackled both problems by providing training and equipment to secondary school librarians for using telecommunications to expand the resources of the libraries and create active learning centres. Librarians were charged with forming partnerships with other educators to integrate the technology into the curriculum and thus open the wealth of the global information resources to all students. New models for education demand active learning environments for exploring knowledge rather than memorization. This approach of building a centralized information centre with the librarian as a facilitator is a natural and exciting approach to curricular innovation using information technology.
\end{abstract}

Main conference themes: learner centred learning

Educational areas: secondary education

Study topics:

Secondary keywords: collaborative learning, library, information

retrieval, networks, telecommunications 


\section{INTRODUCTION}

The rapidly evolving Information Age dictates fundamental changes in societies and their educational systems. Modern information technologies have developed to a point where the ability to retrieve and use information intelligently is becoming a fundamental life skill. Traditional educational curricula based on textual content and curricula which limit learning to internalizing a small core of fundamental information [1], no longer prepare students to cope in societies in which they have access to an ever-increasing wealth of knowledge. Telecommunication technologies have emerged which provide virtual global access to an endless sea of information far beyond what is found within the physical boundaries of schools. Education must be restructured to achieve information literacy [2] and to develop mental and social skills related to using and retrieving information productively.

The school library thus inherits a new, centralized role in the educational process. The concept of the virtual library has emerged [3]. In this library students can access powerful databases, noted experts, others in distant places, and collaborate with the world using a phone line and communications software.

Few precollege educators and librarians have experience and training with these technologies and in methods for using them as part of the curriculum. In this paper one project aimed at integrating telecommunications into the curriculum of secondary schools by training school librarians to be facilitators is described. The project represents true collaboration with the entire community and sharing of resources to achieve the single-minded goal of improvement of education.

\section{BACKGROUND}

Many teachers in East Baton Rouge Parish School District in Louisiana of the United States were using computers in their classrooms. Most classrooms were equipped with computers and some instructional software. Few schools were equipped with phone lines for instructional use. Only a few of these educators had incorporated distance learning or telecommunications into their teaching methodology.

The computer science teacher at a secondary school had participated in a federally funded training program at a state university in informatics education and telecommunications, and had already done significant work to share his expertise with his school and the community. This included involving his students in setting up and maintaining a Waffle [4] bulletin board and local 
electronic mail system to which, at least theoretically, the entire school district had access. At the same time he began to work with other teachers in his school to include telecommunications projects in their teaching. The school librarian likewise learned to use the Internet to enhance the library and research skills of the students, and was eager to extend this wisdom to other librarians in the school district.

With the support of the district library supervisor and administrators at the magnet school these two teachers worked to gather resources and provide training for other secondary school librarians in the district to use telecommunications, with particular emphasis on tapping into the wealth of information available on the Internet. The school district was in economic distress. Most of the school libraries had undergone severe budget cuts and had not been able to maintain traditional resources such as periodical subscriptions or newspapers, once thought to be essential. With a small investment in equipment and phone lines schools administrators could provide libraries with access to these and many more resources without having to directly procure them and store them on site.

The Internet offered a global network of networks linking approximately 300,000 host computers [5] with endless resources for students and teachers at all levels. Within the United States the Internet had become a major political issue with providing access to this 'information highway' a major agenda item of the new national leadership. The Internet was already quite visible in American schools. In 1991, it was estimated that more than $30 \%$ of North American schools had access to educational telecommunications resources, including the Internet. At the same time approximately one percent of the world's 15 million Internet users were thought to be K-12 (secondary education) classroom teachers [6]. The estimates for growth in these areas were astronomical. It was easy to see that the Internet had the potential to be a major force in American education and to significantly change infrastructure of society and American schools.

Few of the school libraries were equipped for telecommunications and none of the other librarians had any experience using the Internet. Most had heard of the Internet and were curious about it, but had little time for extensive courses or training. They also were rather isolated in their schools and had little readily available on-site technical support. A model had to be developed for attacking some of these fundamental problems as well as for providing content.

\section{Participant description}

The project was designed to train secondary school librarians in the use of telecommunications resources, particularly those available through the Internet. A core group of librarians was to participate in the initial training. These 
librarians were then to be trainers themselves and help in preparing others in the school system This would also provide critical research resources to an economically troubled school district and help in the creation of local support systems for the librarians as they ran into stumbling blocks on the way down the information highway.

A key component of the project was gathering administrative support for the project. Foremost among these was the support and encouragement of the district library supervisor who enthusiastically took over many of the administrative details of working with the individual school administrators and librarians participating. A letter of information was sent to each secondary school in the area about the project inviting them to participate. Ten schools submitted the formal letters of agreement and formed teams which attended the training sessions. To participate the school had to demonstrate its support of the project in several ways:

- The principal of the school had to agree to provide the equipment, phone lines and physical resources needed to link to a host computer.

- The school librarian agreed to participate in 6-8 two-hour training sessions held in the afternoon after school hours.

- Another teacher at the school also had to volunteer to participate and to provide technological support on-site to the librarian. Typically this person was the computer science teacher or some other teacher with a good deal of experience using technology in the classroom.

- The librarians hat to agreed to try and get others at the school involved in using the Internet once they were comfortable with the system.

Another hurdle involved acquiring Internet accounts for each school. The school district itself was not able to incur the financial liabilities involved in acquiring its own Internet node. The schools already using Internet were doing so through involvement with the local universities which had already provided accounts to specific teachers for targeted projects. Fortunately the local universities had professors involved with the schools in active ways who managed to procure the new accounts for this project. The university faculty also served as advisors and assisted with the planning of the training.

The real key, of course, consisted of the two teachers leading the project. They were totally volunteering their time. In addition to directing the training they answered countless calls for help during the year and managed the local network. Such enlightened leadership is often needed to affect real systematic change in any educational system.

The project, as are the resources of the Internet, was open ended. The project managers had to adjust plans over time to see how far the librarians 
could go over a period of time without stretching them too thin and losing the majority of them in a flurry of activity.

\section{Project sessions}

The training sessions were held in the libraries of local secondary schools. Beginning sessions were dedicated to establishing e-mail connections between all parties and training the participants to use e-mail. The librarians first learned to use the user friendly district Waffle system to communicate before tackling the more sophisticated Internet systems.

Establishing electronic mail was a major task. Some schools were just setting up equipment and had difficulty getting all pieces of equipment to work together. Each school had its own equipment which was not standardized. Many different communications packages were used thus producing confusion over settings, protocols, and grubby details. Once these obstacles were overcome the librarians, long physically separated from other professional colleagues, were overjoyed to be in regular contact with each other. As a result many partnerships were formed and a local support group was developed. Having electronic mail established also eased the burden on the training leaders who could provide some elementary support through e-mail and did not have to rely on phone calls or take time from school to visit in person.

Later sessions were devoted to retrieving and accessing information using File Transfer Protocol (FTP) and Gopher, and using software tools such as Archie to search for information [7, 8]. Other topics included using Telnet to access and manipulate remote computers, accessing bulletin boards to reach others with common interests, using mail servers to access information through e-mail and FTP, and accessing newsgroups through USENET and Free-Nets.

\section{Project results}

The project had many positive results far beyond the original vision of the leaders. Many of the librarians gained a fairly good grasp of the Internet and methods for using it as a library resource. At least half of the group actively got others in their schools involved in projects. Some used the project effectively as a public relations tool. Several were able to acquire networked labs for their libraries and create information centres as a result. These funds came through the community awareness of the project and its impact, either from local industries or parent groups which raised funds to enhance the libraries. At the end of the year the librarians collaborated to produce a resource book of projects which can be used to guide others venturing out onto the Internet.

There has been a fundamental change in the role of the school libraries within many of the participating schools and the view of this library within the 
administration. Librarians have also united to support each other and share resources and expertise rather than compete for resources.

The project did not yet reach the goal of producing a set of trainers to extend the methodology to others. These librarians gained enormous confidence during the year, but they are still becoming comfortable with their skills and exploring how they can best adapt their libraries to take full advantage of the technology. More training is needed to reinforce their previous work and demonstrate new technologies and software which is rapidly evolving to facilitate searching and retrieving information, particularly through the use of graphical interfaces.

The project seemed most successful at schools where the local technical expert was willingly and actively involved. Most of the librarians were initially unhappy when the group moved from the friendly local Waffle mail system to the Internet e-mail system. This was due in large part to the obscure command language of the host computers and occasional strange network behaviour. At several sites local experts got involved and located more friendly interface software or wrote menu based shells which automated the login process, and in some cases automated other retrieval and storage commands.

The project had many successes and some problems. Perhaps the most lasting contribution has been the public awareness and support for the project and its continuation. Local industries and other local universities have now become involved. Local corporations have loaned equipment to form a local area network and hardware to allow for multiple dial-in users. One university is providing many Internet accounts and expertise to help the system get its own Internet node. The school system has agreed to provide release time for one of the key teachers in this project to be the local network administrator and has granted the other sabbatical leave to acquire additional technical skills. Plans are underway to extend the training this year at new networked hands-on training sites in local universities and at school libraries.

\section{Problem areas}

As with most innovative uses of technology in education the path was paved with obstacles. Fortunately this project was blessed with an energetic group of pioneers with the determination to make it succeed. Some problems were encountered and solved; some remain to be solved. A listing of some of these could be useful to others embarking on similar journeys.

Lack of a hands-on training facility: The sessions were conducted at a local school library. This library had a single phone line and could only be connected to one computer at a time. Most of the training was by demonstration with some time allocated for participants to take turns trying things out. 
Lack of readable and understandable materials: At the time of this project, print materials on educational telecommunications and the use of the Internet were just beginning to appear. Most of the trade books on the Internet were written in jargon requiring a high level of technical expertise.

Nonfriendly user environments: The schools used their own computers, printers, modems, and communications software. Major problems were encountered in downloading and printing files. Several new ideas will be tested this year to help with this problem.

Lack of on-site technical support: Technical support was a major problem. This has many possible solutions including a district technical coordinator and support staff with full-time responsibilities for curriculum development and technical support.

Compensation for participants and leaders: This was entirely a volunteer effort. The leaders donated enormous amounts of time and energy. The librarians, in turn, also sacrificed a great deal of time.

Source of Internet accounts and access: Few school districts can afford the luxury of being direct Internet hosts. Most educational projects involving the Internet therefore involve partnerships with universities, public agencies or private industry to provide access.

Security of host computers: Security of systems remains a concern in the project. The librarians themselves are to be the owners of the accounts. They cannot, therefore, generally pass out their logon ids and passwords to students who might misuse the system. This creates a great problem in getting others to use the Internet.

\section{CONCLUSIONS}

A group of educators in one economically distressed school system collaborated to bring new resources to the community through the use of telecommunications. Internet sites were established at school libraries and librarians were trained to use telecommunications to enrich the resources of the libraries. Students and teachers were solicited to join the world of Internet and explore the ever expanding horizons of the information highway and global community.

The project evolved out of several grass-roots efforts which had already been started by enlightened pioneers in the school district. These energetic individuals enlisted the support of the community to move toward their vision. 
Schools, libraries and curricula are now being restructured to create a system with information literacy as a fundamental component. Local universities are changing the nature of teacher training to support these active learning environments. The community is now committing real resources so that the project can continue and move forward.

Partnerships between teachers, administrators, universities and industries were essential to getting this project of the ground. These remain essential for perpetuation and continued development. Fortunately the district is committed to change and support of the project.

This type of partnership is often needed to created change in educational systems. Education and educational systems are fundamental components of most societies and must adapt to meet the needs of the societies. Resources are usually scare and teachers are trained for the present and not the future. Thus reform in education often involves major reform in teacher training. Training teachers and students to be lifelong learners is essential to growth in education systems. It is in this area that information technology plays a pivotal role.

Training students and teachers to deal with this information explosion has become a national priority in many countries. As we head down the information highway we must continue to remember why we are headed there and educate drivers who are responsible, and skilled users. We must provide usable vehicles and technicians who can help us to navigate in the endless sea of information just across the horizon from the school library of the future.

\section{REFERENCES}

1. Taylor, R. (1991) Communicative Technology and the Emerging Global Curriculum. SIGCUE Outlook, 21 (2) pp. 49-60.

2. McClure, C. (1994) Network Literacy: A Role for Librarians. Information Technology and Libraries, 13 (2) pp. 115-125.

3. Bauwens, M. (1994) What is Cyberspace? Computers in Libraries, 14 (4) pp. $42-48$.

4. Pfaffman, J. (1994) Inexpensive E-Mail Systems for LANs and Dial-up. Recreating the Revolution-Proceedings of NECC'94, The National Educational Computing Conference, Boston, June 13-15, pp. 317-321.

5. Kearsley, G. (1993) Education @ Internet. Ed-Tech Review, (Autumn/Winter), pp. 43-45. 
6. Grandgenett, N. and Harris, J. (1994) Factors Associated with Intensive Telecomputing Use Among Teachers. Journal of Technology and Teacher Education, 2 (1) pp. 3-16.

7. Gilster, P. (1993) The Internet Navigator. John Wiley \& Sons, Inc., New York.

8. Krol, E. (1992) The Whole Internet. O'Reilly \& Associates, Inc., Sebastopol, CA.

9. Harris, J. (1994) File Location and Transfer the Easy Way: Internet-Based Client Software. The Computing Teacher, 21 (6) pp. 30-33. 